\title{
Research on Curriculum Guarantee System of Specialty Cultivation Platform*
}

\author{
Xingjia Liu \\ Department of Thermal Energy and Power Engineering Harbin University of Science and Technology Harbin, \\ Heilongjiang Province, China \\ xj3333333@sina.com
}

\begin{abstract}
According to the market demand of Energy-Saving and Emission-Reduction(ESER) talent in the low carbon economy era, this paper analyzes the contradiction between development of higher education and talent market demand; discusses the necessity and difficulty to establish a talent cultivating platform which adapt to cultivate ESER talents and has a wide caliber and characteristic in higher education talent cultivation; discusses the relationship of wide caliber with adhering to the characteristics; put forwards to the function, content and construction mode of establishment of characteristic cultivation platform and its curriculum guarantee system.
\end{abstract}

Index Terms - Wide caliber cultivation platform; characteristic curriculum guarantee system, ESER talent cultivation, specialty education reform, talent competition

\section{Introduction}

Universities and colleges are an important base to cultivate talents. The students of universities and colleges must serve the society, into the tide of economic development. But the social economy construction needs all kinds of talents. How to cultivate talents to meet market demand is an important part of the higher education reform and development. How to make the students in the talent market competition win a space is an important problem which colleges and universities must face.

Now the national economy is just at a crucial stage of development. The economy transformation from traditional economy increase mode to a low carbon economy mode is going quickly. In this situation, the society puts forward new and higher requirements for talents.

Based on the analysis of talent demand market prospects, combined with the example of thermal energy and power engineering specialty in our university, we explored the construction of a wide caliber specialty talent cultivating platform in order to adapt to the national talent demand for Energy-Saving and Emission-Reduction (ESER) talents. The results are attempted to apply to cultivate compound and applied talents who should not only have the ESER concept and knowledge structure, but also are with a wide adaptability, The results have also the reference significance to other correlative specialty cultivating talents.

\section{Talent Requirements with Social Development and Arrival of Low Carbon Economy Era}

With the further development of the economic globalization and arrival of the low carbon economy era, competition in overall national strength is increasingly fierce. The far-sighted personages in the world are advocating and promoting ESER, in order to promote sustainable economic development[1].To achieve leapfrog development, China needs a large number of talents who have ESER knowledge structure and comprehensive adaptive ability.

To realize the transformation of higher education from elite education to mass education, to meet the social needs for talents, to improve the overall quality of the Chinese nation, the expansion of enrolment scale will undoubtedly play a positive and very important role.

However, with the expansion of higher education enrolment scale, due to the restricting of the speed of economic development and imbalance between higher education development and social needs, the employment contradiction is more and more noticeable. The employment situation of students is increasingly serious. They are facing unprecedented employment pressure. Difficult employment has become one of the protrudent problems of the higher education facing in our country [2], which is a hot issue in current society too. Universities and colleges are the base of cultivating senior talents, the cultivated students must have the ability to serve the society, must be able to meet the needs of the society. Therefore, the modern higher education, in different degrees, is continually expanding the market factors, involved in market operation. In the background of the enrolment expansion to realize the popularization of education, in the today of the low carbon economy era [3], the higher education talent cultivation, without its own characteristics and advantages, it is difficult to cultivate the talents who have higher level and broad adaptability in the numerous competition. And as energy-type specialty which is very close relationship with ESER has to walking in the forefront of ESER talent cultivation.

The quality and characteristics of talent cultivation are the key factor to measure the competitiveness of higher education. Universities and colleges have to consider adjusting the specialty structure, innovating cultivating model according to

\footnotetext{
* This work was supported by Heilongjiang Association of Higher Education (HGJXH B1110521) and Harbin University of Science and Technology
} 
the market demand and cultivate new-type talents who have self-adjustment ability and can do a variety of occupation. And improving the specialty characteristics of the universities and colleges is an important measure to improve the competitiveness of colleges and universities. It is their only way which universities and colleges must pass for their survival and development.

Since thirty years of reform and opening up, the goal of cultivating undergraduate experienced the transformation from "to be both red and expert" to cultivating compound talents who are on the basis of market economy and have "thick foundation, wide calibre". There are gains and losses. The "gains "are, to a certain extent, adapt to needs of the market economy and personal development. The "losses" are the cultivating goals of the convergence cause the structural imbalance in the supply of talents. The talent cultivating goal of undergraduate of "Thick foundation, wide calibre" has contradictions with talent specialization, are not suitable for directly facing the employment market of talent cultivation. Therefore, the localization of cultivating target of different colleges and universities and their specialties should be diverse [4].

A scientific and effective curriculum system is the important foundation and necessary characteristics of talent cultivating in colleges and universities. After specialty calibre expanded, the corresponding characteristic curriculum system must be established. This is an important content of the reform of higher education.

\section{Difficulty and Solution to Establish Wide Caliber Platform of Cultivating Talents}

Broadening the specialty caliber, cultivating talents who have a wide range of competence is one of the important task of talent cultivating in colleges and universities, is also an important part of higher education reform. It is very necessary to enlarge students' knowledge, to improve the students' knowledge structure, to make the students with a wide range of adaptability to meet the requirements of the society for talents. The curriculum system to support this goal is to establish the curriculum system for the wide caliber specialty platform.

And the establishment of a specialty platform for curriculum system is the emphasis and difficulty of this reform. This is because the wide calibre specialty platform curriculum content must cover the main contents of the original several specialties. Therefore, curriculum of specialty platform system with wide calibre should cover the original several specialty major related contents, and can be never built into "assorted cold dishes" of the original several related specialty contents. Obviously, it is very difficult without increasing the class hour. The establishment of specialty platform of curriculum system has greatly influenced on the success or failure of higher education reform.

Therefore, constructing the platform curriculum cannot be the simple accumulation of a few specialty directions, but must have a qualitative leap. That is to say, a specialty platform curriculum system can not be isolated, it must be established into the corresponding security system, should be with the whole curriculum system reform, with the reform of teaching methods, with teaching material construction, and university reform etc, In order to form a set of complete characteristic curriculum system.

The primary contradiction between wide calibre cultivation mode and feature cultivation mode are the following [4] [5]:

1) The contradiction between the diversity and fast changing of social needs and the relative stability and lag of cultivating talents in colleges and universities.

2) The contradiction between the particularity of society needs and the currency of cultivating the talents in colleges and universities.

3) The contradiction between the widespread and interdisciplinary job and special discipline of talents in colleges and universities.

From the view of student employment, on the one hand, cultivating model of wide caliber can increase students' employment, but on the other hand, the employer wants more professional college students. How to solve this contradiction has become the focus problem plaguing the talent cultivation in colleges and universities.

The aim of talent cultivation in colleges and universities, in the final analysis, is to provide all kinds of talents needed for the construction of the state, is to make our country form strong competitiveness under the economic globalization. As a college or university has to run school for industry, but can't run school for single industry like the original, but run school for many industries of a given area. This requires the wide calibre teaching. But at the same time, attention should be paid to prevent exaggerated significance of the "general knowledge "education, to wishful thinking that the "general knowledge" can be achieved, but the actual cultivating can not realize the so-called "general knowledge" at all. The result is out of touch with the real needs of the industry, and greatly decreased the function for the development of the industry to provide human resources and scientific and technological support. This not only will influence the student employment, but also will seriously affect the competitiveness of colleges and universities, and even affect the survival and development of the colleges and universities.

To solve these problems, we should focus on the following work:

1) To discriminate, looking for accurate positioning: For the high level of key university, the calibre of cultivating specialty talent can be wider. The wider specialty calibre cultivating in undergraduate stage can lay a good foundation for students entering the postgraduate stage, but also can open up a wider employment channels because the university reputation advantage.

For the general higher university, their education level is relatively lower. The range to broaden specialty talent cultivating calibre should be smaller. At the same time of the appropriate to expand specialty calibre, the main consideration should be specialty counterparts, to enhance applicative 
specialty knowledge education, so as to make the graduate's employment quickly start.

In a word, specialty orientation has respect to the success or failure of cultivating talent. Specialty positioning must be accurate, unique, cannot follow the same pattern. It should form a complete scientific system with the talent cultivating plan and curriculum system.

2) Taking a variety of cultivating mode, realizing the diversification of cultivating goals: From the social demand for talent view, social demand is diversity, not only needs for the research talents, and the needs for technical talent, also needs for compound talents.

From the higher education itself, the form of higher education is various, the university type is various. The diversity show up as the variety of cultivating objectives, the variety of quality standard, the variety of cultivating pattern, etc.

The diversified cultivating objectives will help to accurately position of target. The targets to research type, technology type, compound type have obvious differences, should adopt different cultivating modes. So, according to the different cultivating goals, to adopt a different cultivating method can fully meet the diversified needs of social and diversified cultivating objectives. This is very important for universities and colleges to form their own characteristics and improve talent competitiveness.

\section{Construction of Wide Characteristic Specialty Platform and Its Curriculum Guarantee System}

It is an important content of the teaching reform of the higher education to broaden the specialty calibre, but also to embody the characteristics of talent cultivation, to form strong competitiveness. And the curriculum system is essential. We should start with the following aspects:

A. Widening Caliber and Adhering to Characteristics Simultaneously, Establishing Specialty Platform curriculum System

Broadening the specialty calibre to enlarge students' knowledge lays the foundation of cultivating talents. Adhering to the characteristic education to improve the students' social competence plays an important role in the participation in the social and international competition.

The formation of platform curriculum system is an important action to expand the specialty calibre. In order to effectively broaden the specialty calibre, the platform curriculum system must cover the related contents of original every specialty. In subjects, different universities should establish their relevant platform curriculum system which can reflect their characteristics and advantages based on their development history, features and the actual situation. In the content selection, the platform course can not be built into a simple "assorted cold dishes" of the original several related specialty contents, should have a qualitative leap. the platform course of a university not only be able to broaden the specialty calibre, but also differ from other universities, can reflect their own characteristics, can be closely linked to the social demand, can stand in the forefront of industry development[6].

B. Outstanding specialty Direction Curriculum characteristics, ensuring specialty platform

1) Establishing and Developing Direction mode, Reflecting specialty Direction Characteristics: In order to meet the social demand for talents, to improve the students' adaptability to create conditions, establishment of specialty module should be strived to meet the demand of talent cultivating in all aspects in the direction. Orientation courses should connect with platform courses to guarantee the teaching effect of the platform courses. This can jointly formed a more perfect specialty module of a system, in order to promote the organic combination of specialty calibre broadening and the characteristic cultivating.

In order to adapt to the expansion of the university scale and give full play to the existing resources, combining with the actual situation of the market demand, the universities and colleges should develop specialty direction to suit one's measures to local conditions, to do more with less, to perfect the system of running schools, to do a course system characteristics, but don't go in for grandiose projects, in order to ensure the quality of talent cultivating.

2) With Direction Elective Courses, to Promote Personality Development of Students, to Ensure Cultivating Platform: In order to avoid affecting the development of students' personality due to the expansion of specialty direction, elective courses in related fields should be set for students. Students can take the courses which they like according to their interests and occupation planning. It can promote the development of students' personality, in order to ensure the effect of talent cultivating in the specialty platform.

C. Enhancing Practice Teaching, Strengthening Specialty Platform, to Improve Innovation Ability of Students

To strengthen the cultivation of student's ability, improving the quality of students is an important task for education reform. The practice teaching has great function to improve students' ability. In the teaching plan, hours and contents should be appropriately increased. It can increase the depth for students to understand knowledge, improve their ability to apply knowledge to solve practical problems. This is also conducive to the platform courses and help to improve specialty curriculum teaching effect. Cultivation of students' practical ability and innovative ability are closely related with practical teaching curriculum system to a large extent. Practical teaching link in the application ability and innovation ability of cultivating talent will play an important, irreplaceable role.

\section{Realizing Interconnecting Curriculum System, Supporting Cultivating Platform \\ The curriculum system must be closely linked with the national fundamental policy, must seeking for survival and development with the characteristics. The curriculum should be form a complete system in which the curriculum is to be}


communicated with each other, is to be complemented with each other.

Basic courses, platform courses, orientation courses, elective courses, these courses forming distinct characteristics are difficult. Prominent contradiction is between the specialty broadening and effect raise of application ability. In a limited period, the teaching to all aspects is not possible. But this does not mean that can reduce the quality of teaching. The starting point of the reform of higher education is to achieve the transformation from a simply imparting knowledge to both teaching the knowledge, and improving ability and quality. This will greatly increase the difficulty of teaching undoubtedly. Approach to solve this problem is first to integrate in multi dimension in the content, to make the curriculum system scientific, to make the each part of the course system communicated with each other, to make the connection complemented each other. At the same time, the concept of teachers also must be changed, the construction of teachers must be strengthened, the lack of teaching materials must be solved, the teaching methods must be reformed, the teaching facilities must be increased, etc.

This work itself is very difficult. There is still a need for research and exploration. Therefore, curriculum system must not be done isolated. It must be done with other reform of higher education.

\section{Summary}

In the background of popularization education, if colleges and universities (especially the general ones) want a place in the fierce competition, they must establish and perfect the distinctive curriculum system, which relates to their survival and development. A wide calibre specialty cultivating platform which has distinct characteristics will help to improve the competitiveness of universities and colleges cultivating talents. The establishment of a scientific curriculum system is crucial. Of course, curriculum system operation difficulty is greater, the application effect improving, still needs a lot of work to do. We believe that, with the reform of higher education further deepening and a scientific operational mechanism establishing, perfect and characteristic specialty cultivating platform must be able to plays a great role in talent cultivating in the higher education competition, for the realization of the cultivating goal, and make an important contribution for the energy-saving and emission-reduction.

\section{Acknowledgment}

This work was supported by Heilongjiang Association of Higher Education (HGJXH B1110521) and Harbin University of Science and Technology. The author would like to express my gratitude! At same time, the author wishes to thank all our colleagues in our staff room for their support and help during my researching work.

\section{References}

[1] Li Zhangl, Peng Li. "Developing Low Carbon Society Talent to Lead to Promote Low Carbon Concept", J. Beijing Education (Higher Education) .2010(7)

[2] Qisheng Liu, Bingbing Yan, Guangjun Chen. "Exploring in order to Enhance Employment Competitiveness as the Goal of Application Engineering Talents Cultivation", J. China Electric Power Education, 2011(14).

[3] Junrui Li. "Push on Energy Education in Universities. Promote the Development of Low-Carbon Economy" C. Collected Ppapers of Forum on the Second China Energy, Scientist. USA: Scientific Research Publishing, 2010, pp835-838.

[4] Junxing Cao. Xiaoliang Cheng, Aizhen Sun, Liang Zhao, Mei Huang. "The Evolution and Reflection about the Goal that Undergraduate Training' of 30 Years of Reform and Opening up, J. Journal of ChengDu University of Technology (Social Sciences) ,2008(4),pp29-32.

[5] Bo Qu, Tuo Liu. "Construction of Characteristic specialty and innovation of talent cultivation system",J. China's higher education. 2008 (15).

[6] Xingjia Liu. "Higher education reform and the construction of professional platform class some thinking", J. impart knowledge and educate people. 2001 (5). 